\title{
Tinnitus Interferes With Daily Life Activities: A Psychometric Examination of the Tinnitus Disability Index
}

\author{
Rilana F. F. Cima, ${ }^{1,2}$ Johan W. S. Vlaeyen, ${ }^{1,3}$ Iris H. L. Maes, ${ }^{4}$ Manuela A. Joore, ${ }^{4}$ \\ and Lucien J. C. Anteunis ${ }^{5}$
}

\begin{abstract}
Objectives: Tinnitus Disability Index (TDI) is presented as a novel and brief self-report measure for the assessment of the interference of tinnitus with performance in specific daily life activities. We hypothesized that the TDI is a reliable and valid measure and that tinnitus disability is strongly associated with tinnitus severity, subjective tinnitus intensity ratings, and ratings of general health.
\end{abstract}

Design: Six hundred fifteen tinnitus patients from across the Netherlands completed online a number of questionnaires about their tinnitus, their general health, and demographics. Two samples were extracted by a random split: Sample I $(\mathrm{N}=311)$ for exploratory factor analysis and Sample II $(\mathrm{N}=304)$ for confirmatory analysis, using structural equation modeling. One hundred forty-three of the first included respondents repeated assessment after a 2-wk time interval for test/retest analysis. Regression analyses were employed to investigate construct validity.

Results: Present analyses reveal that tinnitus disability, as measured with the TDI, might be best understood as a single-component construct, that is, one single underlying factor. The TDI is reliable over time, and tinnitus-related disability, as measured with the TDI, is strongly associated with subjective ratings of tinnitus intensity, negatively associated with quality of life ratings, and distress due to tinnitus.

Conclusions: The TDI is a brief and easily administered index measuring a unique construct, namely the experienced interference of the tinnitus with daily life activities, which is invaluable in the assessment and treatment of tinnitus patients.

(Ear \& Hearing 2011;32;623-633)

\section{INTRODUCTION}

Tinnitus can be defined as the continuous perception of a sound without the presence of an external source. It has also been described as phantom auditory perception (Jastreboff 1990) and mostly ringing, beeping, or buzzing sounds are reported. Tinnitus is perceived at least once in life by $30 \%$ of the general population. It has been estimated that up to $15 \%$ of the general population perceives tinnitus constantly, and 6 to $25 \%$ of this group suffers from it on a daily basis (Heller 2003). Severe tinnitus suffering has been associated with audiological dysfunction (hearing loss, hyperacusis), psychological distress (anxiety, depressive symptoms), cognitive dysfunction (disorders in attention and concentration), and characteristics of the tinnitus sound (loudness, pitch) (Andersson 2003; Holgers et al. 2005; Hiller \& Goebel

\footnotetext{
${ }^{1}$ Department of Clinical Psychological Science, Maastricht University, Maastricht, The Netherlands; ${ }^{2}$ Adelante, Centre of Expertise in rehabilitation and Audiology, The Netherlands; ${ }^{3}$ Research Centre for Health Psychology, Department of Psychology, University of Leuven, Leuven, Belgium; and Departments of ${ }^{4}$ Clinical Epidemiology and Medical Technology Assessment and ${ }^{5}$ Otorhinolaryngology \& Head and Neck Surgery, University Hospital Maastricht, Maastricht, The Netherlands.
}

2006). A uniformly legitimate underlying cause has of yet not been discovered (Noble \& Tyler 2007), and different assessment strategies and treatment approaches for chronic tinnitus exist (Jastreboff \& Hazell 1993; McCombe et al. 2001; Zachriat \& Kroner-Herwig 2004; Martinez Devesa et al. 2007). Reliable instruments (questionnaires, structured interviews), rating scales, and audiometric protocols have been developed (Tyler et al. 1992; McCombe et al. 2001; Heller 2003; Hiller \& Goebel 2006) to assess these factors, for it is known that these are the main contributors to the poor general health and functional disturbances in tinnitus sufferers (Erlandsson \& Hallberg 2000; Meikle et al. 2007).

In a recent review on disease-specific health-related quality of life (QoL) instruments used to measure outcomes in tinnitus trials, six commonly used health-related QoL tinnitus instruments were identified (Kamalski et al. 2010). The Tinnitus Handicap Inventory (Newman et al. 1996) has three subscales: functional, emotional, and catastrophic responses to the tinnitus. Both overall and subscale internal consistency were found to be good. The Tinnitus Questionnaire (TQ) (Hallam et al. 2004) has six domains: emotional distress, cognitive distress, intrusiveness, auditory and perceptual difficulties, sleep disturbances, and somatic complaints as a result of the tinnitus. The TQ items are internally consistent; the subscales lack internal consistency however. The Tinnitus Reaction Questionnaire (Wilson et al. 1991) measures distress related to tinnitus and incorporates four domains: general distress, interference, severity, and avoidance of the tinnitus. The focus of these three latter questionnaires is mainly on measuring patient's perception on impaired individual functioning or specific functions as a result of the tinnitus. The Tinnitus Severity Index (Meikle et al. 1995) is a unified measure for tinnitus severity. Two items specifically address the interference of the tinnitus in daily life activities. The Tinnitus Handicap Questionnaire (THQ) (Kuk et al. 1990) assesses patient's perceived degree of handicap due to tinnitus. The THQ has three domains: (1) physical health/ emotional status/social consequences, (2) hearing and communication, and (3) personal viewpoint on tinnitus. Seven items specifically address the interference of the tinnitus on daily activities; four of which address hearing difficulties, two items address social interactions, and one item addresses sleep difficulties because of the tinnitus. The THQ subscales fails on internal consistency. The Tinnitus Severity Questionnaire (Coles et al. 1991) is a short unified measure with two items specifically addressing interference of the tinnitus, one item on sleeping habits and one on impairment in concentration. Table 1 lists these six instruments along with their characteristics and psychometric quality. 
TABLE 1. Characteristics and psychometrics of existing Tinnitus HR-QoL instruments

\begin{tabular}{|c|c|c|c|c|c|}
\hline Instrument & Items & Scoring & $\begin{array}{l}\text { Construct } \\
\text { Validity }\end{array}$ & $\begin{array}{l}\text { Reliability } \\
\text { (Test-Retest) }\end{array}$ & Subscales \\
\hline $\begin{array}{l}\text { Tinnitus Handicap Inventory } \\
\text { (THI) }\end{array}$ & 25 & $\begin{array}{l}\text { (0) never } \\
\text { (2) sometimes } \\
\text { (4) yes }\end{array}$ & + & + & $\begin{array}{l}\text { Functional, emotional, catastrophic } \\
\text { responses }\end{array}$ \\
\hline Tinnitus Questionnaire (TQ) & 52 & $\begin{array}{l}\text { True } \\
\text { Partly true } \\
\text { Not true }\end{array}$ & + & + & $\begin{array}{l}\text { Emotional distress, cognitive } \\
\text { distress, intrusiveness, auditory } \\
\text { perceptual difficulties, sleep } \\
\text { disturbance, somatic complaints }\end{array}$ \\
\hline $\begin{array}{l}\text { Tinnitus Reaction Questionnaire } \\
\text { (TRQ) }\end{array}$ & 26 & $\begin{array}{l}\text { (0) not at all } \\
\text { (4) almost }\end{array}$ & + & + & $\begin{array}{l}\text { General distress, interference, } \\
\text { severity, avoidance }\end{array}$ \\
\hline Tinnitus Severity Index (TSI) & 12 & $\begin{array}{l}\text { (0) never } \\
\text { (4) always }\end{array}$ & - & + & None \\
\hline $\begin{array}{l}\text { Tinnitus Handicap Questionnaire } \\
\text { (THQ) }\end{array}$ & 27 & $\begin{array}{l}\text { (0) strongly disagree } \\
\text { (100) strongly agree }\end{array}$ & + & + & $\begin{array}{l}\text { Physical health/emotional status/ } \\
\text { social consequences, hearing } \\
\text { and communication, personal } \\
\text { viewpoint }\end{array}$ \\
\hline
\end{tabular}

The aforementioned instruments were developed to assess tinnitus suffering or burden for clinical discriminative purposes and are commonly used to evaluate clinical trials in tinnitus research. None of them has been validated on test responsiveness yet. All of the six instruments incorporate items assessing emotional and attentional impairment because of the tinnitus, and questions about hearing difficulties and impaired social interactions are often included as well. Three of the six instruments specifically address the interference of the tinnitus on specific daily life activities. It is interesting that an assessment of the impact of tinnitus on daily life, or the interference of the tinnitus with specific daily life activities without the confounding of emotional, physical, or attentional dysfunctioning, has not yet been developed.

Chronic tinnitus is not only aversive but also interferes with daily life activities, which is possibly due to the attentiongrabbing nature of the tinnitus. It has been suggested that the characteristics of the tinnitus sound in combination with the psychological make-up of the individual are the main factors contributing to tinnitus annoyance (Tyler et al. 1992). Others have indicated that interference of the tinnitus is primarily associated with deficits in attentional and memory processes (Andersson \& McKenna 2006; Stevens et al. 2007) and that only weak associations exist between tinnitus annoyance and tinnitus characteristics (i.e., loudness and pitch) (Andersson 2003; Jastreboff \& Hazell 2004). Studies in other research areas have also shown that the level of disability in chronic disease is weakly associated with stimulus intensity. Chronic pain patients, for example, do not differ in their reported pain intensity from individuals with chronic pain who are not seeking health care but do differ in the extent to which the pain is disabling in daily life as was reflected in the levels of distorted cognition, pain-related distress, and activity levels (Reitsma \& Meijler 1997).

In accordance with previous findings about parallels between chronic pain and chronic tinnitus (Tonndorf 1987; Folmer et al. 2001), it is currently hypothesized that disability measures assessing chronic pain might be similarly relevant in assessing tinnitus-related disability. The Tinnitus
Disability Index (TDI) is presented as a self-report measure for disability due to tinnitus on daily life activities. An advantage of the TDI is that it is a brief and easily administered instrument, assessing functional disability on seven intelligible life domains.

The TDI is modeled after the Pain Disability Index (PDI), which was developed as an inventory of pain interference in daily life. The PDI has shown to be a reliable, valid, and brief measure for pain-related disability (Pollard, 1984; Tait et al. 1990). The factor structure of the PDI has been frequently investigated, and both a one-factor and two-factor structure have been suggested. The two-factor solution indicates that the PDI assesses disability due to pain in two separate activity categories: voluntary activities (family/home responsibilities, recreation, social activity, occupation, and sexual behavior) and obligatory activities (self-care and life-support activity) (Jerome \& Gross 1991; Gronblad et al. 1993; Tait \& Chibnall 2005; Gauthier et al. 2008).

The purpose of the present study was first to investigate the psychometric properties of the TDI. Reliability, validity, and factor structure of the TDI were assessed in a cross-sectional data set of people suffering from tinnitus. It is hypothesized that the TDI has a similar underlying factor structure, as has been previously suggested for the PDI. Second, it was expected that tinnitus disability, as measured with the TDI, would be associated with tinnitus-related distress, subjective tinnitus intensity ratings, and ratings of general health, but that correlations among these variables would be modest.

\section{PARTICIPANTS AND METHODS}

\section{Participants}

Participants were recruited via an advertisement on the websites of the Dutch Association for hearing disorders (www.nvvs.nl) and the Dutch Tinnitus Platform (www. tinnitus.nl). The latter is an organization uniting tinnitus healthcare professionals. Respondents were included in the study in case they were able to hear a continuous tinnitus at the moment; either bothersome or not. Respondents $(\mathrm{N}=$ 
791) from across the Netherlands were included from November 2008 until April 2009. Data from 615 participants were used in current analyses, since there was $22 \%$ primary nonresponse $(\mathrm{N}=176)$. The primary nonresponders were individuals who registered for the present study but refrained from eventual participation. By using a random split method, two samples were extracted from the larger sample. Sample I $(\mathrm{N}=311)$ was used to perform an exploratory factor analysis, while confirmatory analysis was performed on Sample II ( $\mathrm{N}=304)$. To investigate test-retest reliability of the TDI, 250 respondents were asked to complete the assessment battery for a second time 2 wks later, of which 143 complied. Last, construct validity was investigated by using a second subsample $(\mathrm{N}=382)$ of individuals who also rated the experienced intensity of the tinnitus sound.

\section{Procedure}

A special website was developed to provide additional information about the study and for registration purposes. Participants could enter the study by filling in name, telephone number, and email address on a special page on the Website of Maastricht University. They were contacted subsequently and after informed consent was obtained, personal login codes were sent by email. These codes gave participants access to an internet-based electronic environment named "Emium" (Janssen 2008), enabling completion of the battery of tests online. Participants were able to log out if necessary and $\log$ in again at a later time but were requested to start the test within a week and to complete the test within 1 day. Respondents who were not able to complete the questionnaires on-line were enabled to fill them in on paper off-line by sending copies of the questionnaires by postal mail with a free return address envelope. The order of administration of the tests was fixed; participants were not able to change the order in which the questions were presented. Each new questionnaire was presented with a clear beginning and end, always starting with an instruction for this particular questionnaire and ending with thanking the participant and a message that the next questionnaire would start. The research protocol was approved by the ethical board of the Faculty of Psychology and Neuroscience of the Maastricht University.

\section{Measures}

The assessment battery consisted of the TDI, the TQ (Baguley et al. 2000; McCombe et al. 2001), tinnitus intensity ratings on Visual Analog Scales (VASs), and a questionnaire about demographics.

Disability due to tinnitus was assessed by the TDI, an adapted version of the PDI (Tait et al. 1990; Tait \& Chibnall 2005) consisting of seven items corresponding to seven major aspects of daily life: family/home responsibilities, recreation, social activity, occupation, sexual behavior, self-care, lifesupport activity (see Appendix). Each of these seven scales is rated on a horizontal numerical scale $(0-10)$ with the following anchors: 0 corresponds to "no disability" and 10 is equivalent to "total disability." The advantages of the TDI, as compared to existing measures, is that it is concise, easily administered and interpreted, and scores are expected to serve as a valid index for the extent to which tinnitus represents a problematic factor in an individual's daily life.
Distress caused by the tinnitus or tinnitus severity was assessed by the TQ. The TQ consists of 52 items rated on a 3-point scale and assesses the psychological distress associated with the tinnitus. Items cover a broad range of negative psychological consequences, auditory perceptual difficulties, sleep disturbances, and somatic complaints as a result of tinnitus. Psychometric properties of different language versions of the TQ have shown to be satisfactory in different languages (Baguley et al. 2000; McCombe et al. 2001). The internal consistency of the TQ in the current sample was excellent (Cronbach's alpha $=0.94$ [total sample]; 0.94 [Sample I]; 0.94 [Sample II]).

QoL was assessed by the Short Form-36 (SF36) (Hays et al. 1993; Ware et al. 1998; Mosges et al. 2008), which comprises 36 items to assess various aspects of QoL and eight subscales can be calculated: physical functioning, bodily pain, role limitations due to physical health problems, role limitations due to personal or emotional problems, emotional well-being, social functioning, energy/fatigue, and general health perceptions. Two general subscales can be derived from the eight subscales: physical and mental health. The internal consistency of the SF36 was excellent (Cronbach's alpha of the eight subscales ranged from 0.83 to 0.94 [total sample]; Cronbach's alpha [total score] $=0.94$ [Sample I]; 0.94 [Sample II]). The SF36 has been used before in comparative studies in the hearing disabled population and possesses good discriminant validity (El Refaie et al. 2004; Mosges et al. 2008).

Tinnitus intensity was assessed by three VAS. The VAS intensity ratings were included to assess subjects "worst," "least," and "usual" tinnitus ratings. The following three questions were rated: "How do you judge the intensity of your worst tinnitus?", "How do you judge the intensity of your mildest tinnitus?", and "How do you judge the intensity of your tinnitus in general over the past few days?" The VASs were provided with the anchors: "not intense at all" and "the most intense sound imaginable." The tinnitus intensity VAS showed good internal consistency (Cronbach's alpha $=0.82$ [total sample]; 0.81 [Sample I]; 0.82 [Sample II]).

Demographics were assessed by a separate questionnaire, including questions about age, gender, education, duration of complaints, hearing loss, health care history, current treatment, professional life, and sick leave history.

\section{Statistical Procedures}

Multivariate outliers were identified through Mahalanobis distance $(p<0.001)$. Three cases of Sample I and two cases of Sample II were found to be outliers and were deleted. Both samples contained cases with missing responses on the TDI. Since this is the measure under investigation, four cases from Sample I and three cases from Sample II with missing data on the TDI were excluded from further analysis. To perform exploratory analysis, a principal component analysis was carried out on the calibration sample (Sample I) to assess factor structure, using SPSS 15.0 for Windows (SPSS 2009). To perform the confirmatory analyses, structural equation modeling was employed using AMOS version 17.0 (Arbuckle 2006) on the validation sample (Sample II). Second, internal consistency of the TDI was assessed on the total sample $(\mathrm{N}=609)$. Third, test-retest reliability of the TDI was investigated using data 
from a subsample of participants who were invited to complete the battery of tests once again, with a mean interval of 4 wks $(\mathrm{N}=146)$. Fourth, possible differences in demographic properties were investigated first using parametric and nonparametric methods. Fifth, construct validity was examined using Pearson correlation coefficients among the measures of tinnitus disability (TDI), tinnitus severity (TQ), and QoL (SF36). Last, stepwise regression analyses were carried out with tinnitus disability as the dependent variable and sociodemographics, distress due to tinnitus, tinnitus intensity, and general QoL as independent variables.

\section{RESULTS}

\section{Participants}

To investigate whether the two samples differed in demographic characteristics, a series of parametric (age and employment) and nonparametric (gender, marital status, educational level, tinnitus duration/location, and hearing disorder) analyses were performed. The two samples were not significantly different in age $(T[285]=-0.085, p=0.93)$ and employment status $(T[285]=0.174, p=0.86)$ and not in distributions in gender, marital status, educational level, tinnitus duration/ location, and hearing disorder $\left(\chi^{2} \leq 3.2, p \geq 0.08\right)$. Table 2 displays demographic data of both samples.

\section{Exploratory Factor Analysis}

A principal component analysis on the seven items of the TDI from the calibration sample was performed. Only one factor was found matching the eigenvalue $=$ one criterion. Consequently, rotation was not performed. The one-factor structure accounted for $>60 \%$ of total variance, and the KMO measure of sampling adequacy was considered to be excellent (0.87).

Since previous results in pain research showed a two-factor solution of the PDI, a second principal component analysis was performed on the calibration sample, in which two-factor solution was forced. The two factors were internally consistent; the Kaiser-Meyer-Olkin (KMO) measure of sampling adequacy was, again, considered to be excellent (0.90). Since both factors were allowed to somewhat correlate, oblique rotation was performed, resulting in the factor loadings from the pattern matrix. The two-factor solution accounted for $72 \%$ of total variance. Factor 1 accounted for $62.13 \%$ (eigenvalue $=4.35$ ) and factor $210.49 \%$ (eigenvalue $=0.74$ ) of the total variance. Table 3 displays the factor loadings of both the one- and two-factor solutions. It is surprising to note that inspection of loadings shows the first factor to include the first four items of the TDI, instead of the expected five first items assessing voluntary activities in the PDI, and the second factor included the last three items, instead of the last two items reflecting obligatory activities in the PDI. These results might indicate a slightly different underlying factor structure in tinnitus disability as measured with the TDI in tinnitus patients compared with pain disability as measured with the PDI in chronic pain sufferers. The intercorrelation between both factors was relatively high (Pearson $r=0.61, p=0.000$ ).
TABLE 2. Descriptives of Sample I (calibration sample) and Sample II (validation sample)

\begin{tabular}{|c|c|c|}
\hline Sample & 1 & II \\
\hline Total N & 311 & 304 \\
\hline Outliers & 3 & 2 \\
\hline Missing (deleted listwise) & 4 & 3 \\
\hline $\mathrm{N}$ & 304 & 299 \\
\hline Age, mean (SD) & $51.5(11.6)$ & $51.3(12.5)$ \\
\hline \multicolumn{3}{|l|}{ Gender } \\
\hline Male & $185(61)$ & $171(57)$ \\
\hline Female & $119(39)$ & $128(43)$ \\
\hline \multicolumn{3}{|l|}{ Duration (yrs) } \\
\hline$<1$ & $36(12)$ & $31(10)$ \\
\hline $1-5$ & $111(37)$ & $104(35)$ \\
\hline $5-10$ & $61(20)$ & $52(17)$ \\
\hline$>10$ & $96(32)$ & $112(37)$ \\
\hline \multicolumn{3}{|l|}{ Marital status } \\
\hline Single & $38(12)$ & $42(14)$ \\
\hline Living together & $42(14)$ & $39(13$ \\
\hline Married & $199(65)$ & $197(66)$ \\
\hline Divorced & $20(7)$ & $20(6)$ \\
\hline Widowed & $5(2)$ & $1(1)$ \\
\hline \multicolumn{3}{|l|}{ Education } \\
\hline Primary/secondary & $6(2)$ & $7(2)$ \\
\hline High school & $100(33)$ & $103(34)$ \\
\hline Intermediate & $63(21)$ & $64(21)$ \\
\hline Higher & $135(45)$ & $125(42)$ \\
\hline \multicolumn{3}{|l|}{ Current treatment } \\
\hline Yes & $71(23)$ & $60(20)$ \\
\hline No & $233(77)$ & $239(80)$ \\
\hline \multicolumn{3}{|l|}{ Employment } \\
\hline Yes & $189(62)$ & $187(63)$ \\
\hline No & $115(38)$ & $112(37)$ \\
\hline \multicolumn{3}{|l|}{ Location of tinnitus } \\
\hline Left & $71(23)$ & $64(21)$ \\
\hline Right & $39(13)$ & $50(17)$ \\
\hline Bilateral & $153(50)$ & $146(49)$ \\
\hline Middle & 41 (13) & $39(13)$ \\
\hline \multicolumn{3}{|l|}{ Hearing disorder } \\
\hline Yes & $139(46)$ & $149(50)$ \\
\hline No & $165(54)$ & $150(50)$ \\
\hline \multicolumn{3}{|l|}{ Location of hearing disorder } \\
\hline Left & $38(27)$ & $38(26)$ \\
\hline Right & $15(11)$ & 27 (18) \\
\hline Bilateral & $86(62)$ & $84(56)$ \\
\hline \multicolumn{3}{|l|}{ Treatment } \\
\hline Ear, nose, throat physician & $19(27)$ & $16(27)$ \\
\hline General practioner & $4(6)$ & $2(3)$ \\
\hline Audiological center & $25(35)$ & $20(33)$ \\
\hline Physical therapist & $2(3)$ & $2(3)$ \\
\hline Other & $21(30)$ & $20(33)$ \\
\hline
\end{tabular}

Values are given as $n(\%)$.

\section{Confirmatory Factor Analysis}

The adequacy of the one-factor and two-factor solutions was tested on the validation sample by performing Confirmatory Factor Analyses. In addition, the two-factor solution, previously reported in studies with chronic pain patients, was tested. The assumptions of multivariate normality and linearity were assessed, and maximum likelihood was used to estimate all the models.

First, the one-factor solution was investigated. The hypothesized model was considered a marginal fit, $\chi^{2}(14, \mathrm{~N}=$ 
TABLE 3. Factor loadings of the one- and two-factor solutions from exploratory factor analysis

\begin{tabular}{|c|c|c|c|c|}
\hline \multirow[b]{2}{*}{ Item } & \multirow[b]{2}{*}{ Content Summary } & \multirow{2}{*}{$\begin{array}{c}\text { One } \\
\text { Factor } \\
\text { I }\end{array}$} & \multicolumn{2}{|c|}{ Two Factors } \\
\hline & & & 1 & II \\
\hline 1 & Family/home responsibilities & 0.83 & 0.69 & 0.21 \\
\hline 2 & Recreation & 0.82 & 0.86 & 0.05 \\
\hline 3 & Social activity & 0.80 & 0.95 & -0.12 \\
\hline 4 & Occupation & 0.80 & 0.85 & 0.04 \\
\hline 5 & Sexual behavior & 0.77 & 0.19 & 0.63 \\
\hline 6 & Self-care & 0.70 & 0.34 & 0.55 \\
\hline \multirow[t]{2}{*}{7} & Life-support activity & 0.69 & -0.12 & 0.97 \\
\hline & Explained variance & $60.13 \%$ & $62.13 \%$ & $10.49 \%$ \\
\hline
\end{tabular}

302) $=65.98, p<0.001$, Comparative Fit Index $(\mathrm{CFI})=$ 0.96 . Considering the large sample, the significant $\chi^{2}$ was expected. Post hoc model modifications were performed to develop a better fit resulting in a more parsimonious model. Figure 1 shows the hypothesized model where the circles represent the latent variables and the rectangles represent the measured variables. On the basis of the Lagrange multiplier test $(p<0.001)$, three covariances were added to the model between the error terms corresponding to items 6 (self-care) and 7 (life-support activity), items 5 (sexual behavior) and 7 (life-support activity), and items 3 (social activity) and 4 (occupation). Strong support was found for the final model, $\chi^{2}(11, \mathrm{~N}=302)=16.96, p=0.109$, and a robust $\mathrm{CFI}=0.995$.

The same analyses were repeated to test the two-factor solution found in the exploratory factor analysis in which a second factor was forced. Three covariances, based on the Lagrange multiplier test $(p<0.001)$, were added between the error terms corresponding to items 5 (sexual behavior) and 6 (self-care), items 4 (occupation) and 7 (life-support activity), and items 3 (social activity) and 4 (occupation), which resulted in a more parsimonious model (see Fig. 2). Again, strong support was found for this two-factor solution, with slightly better indices on first sight, $\chi^{2}(10, \mathrm{~N}=302)=$ $11.79, p=0.299$, and robust CFI $=0.998$.

A third analysis was carried out in which the two-factor model, derived from previous psychometric research of the PDI (voluntary versus obligatory activities), was tested. Post hoc model modifications were needed for a more parsimonious model, and based on the Lagrange multiplier test $(p<$ 0.001 ), a total of five covariances were added. Figure 3 illustrates the final model with covariances between the error terms corresponding to items 5 (sexual behavior) and 7 (life-support activity), items 3 (social activity) and 4 (occupation), items 4 (occupation) and 7 (life-support activity), items 2 (recreation) and 5 (sexual behavior), and items

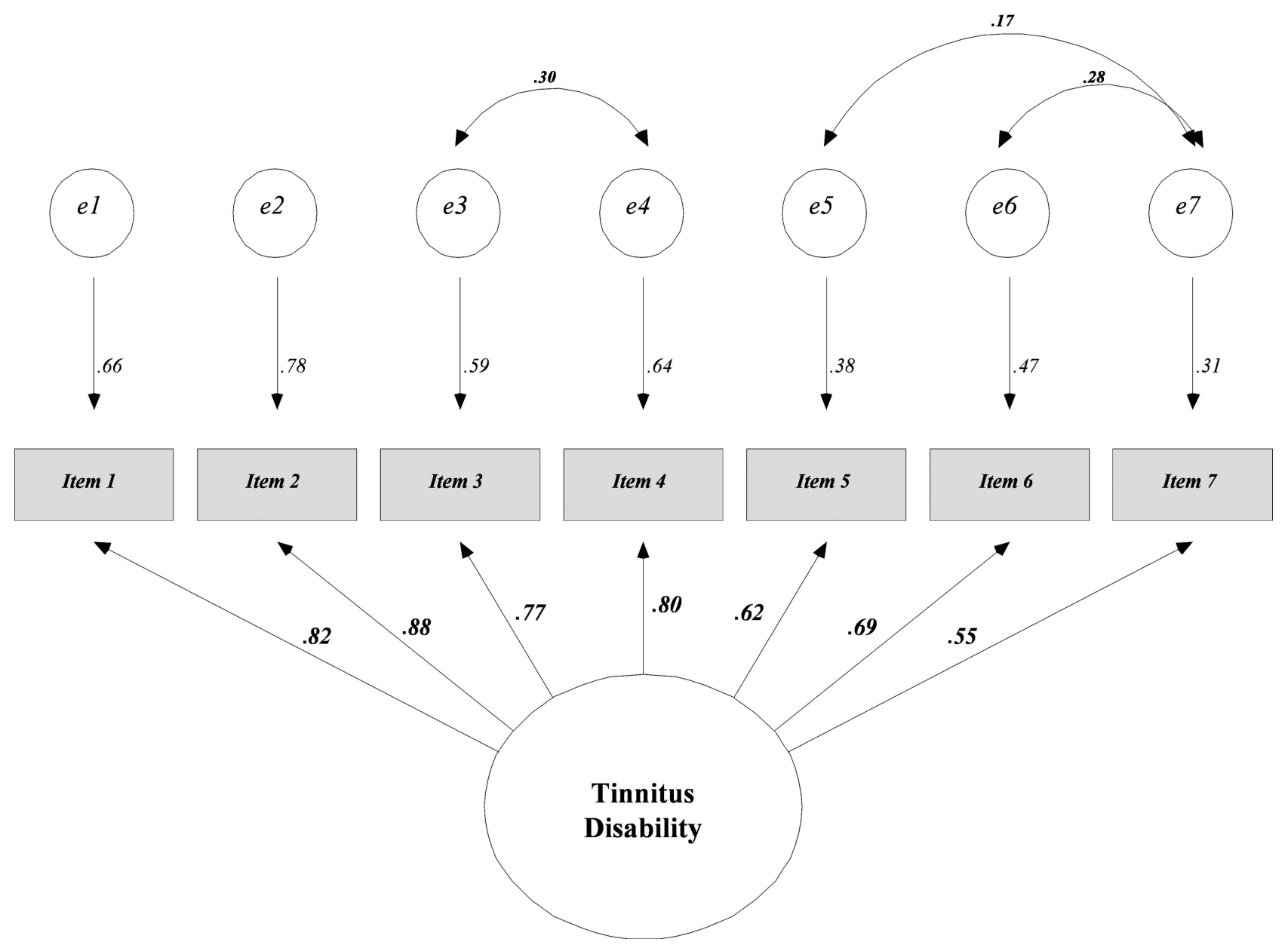

Fig. 1. One-factor model with standardized estimates and added covariances. 


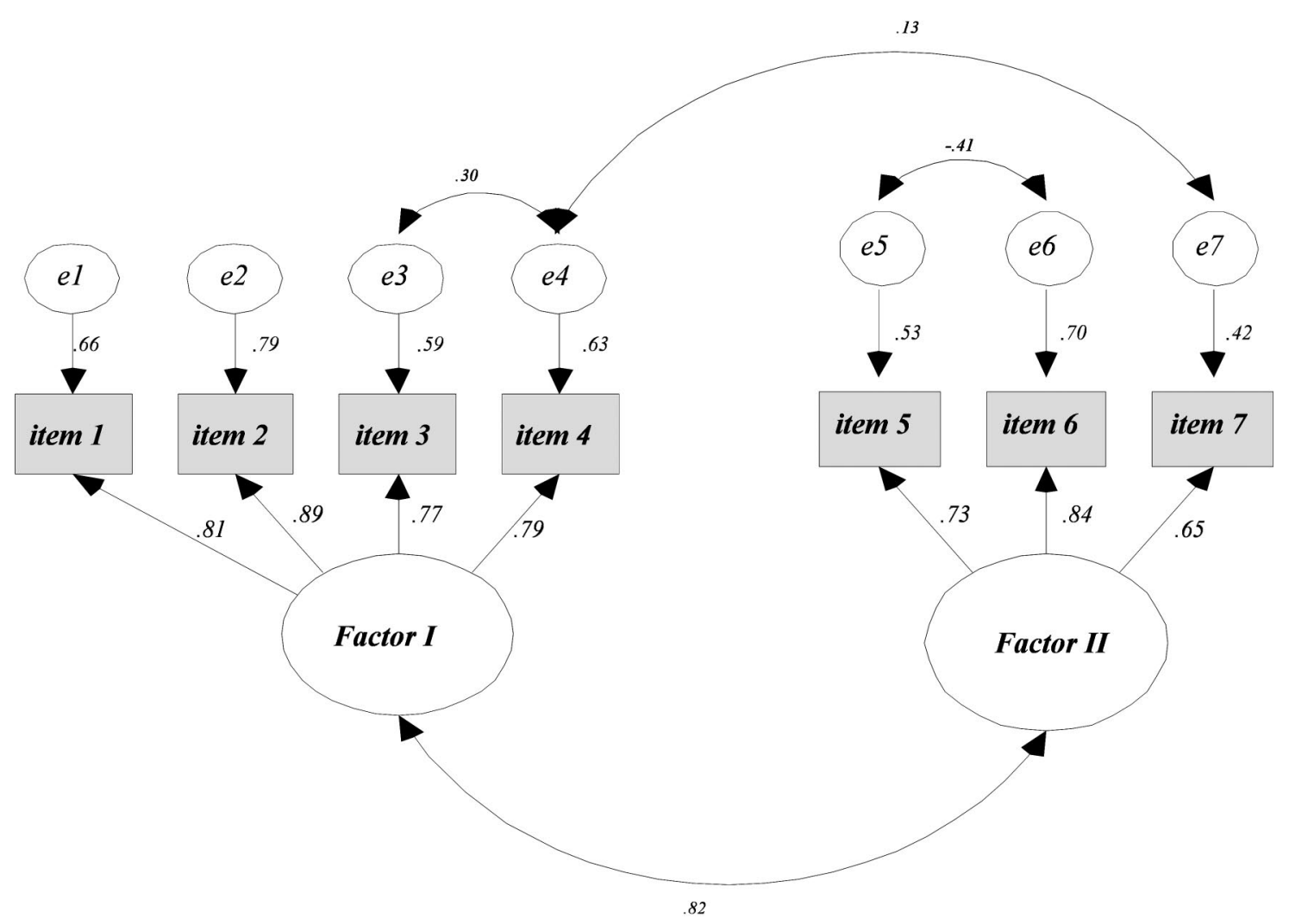

Fig. 2. Two-factor model, from Exploratory Factor Analysis, with standardized estimates and added covariances.

1 (family/home responsibilities) and 3 (Social activity). Again, robust indices, $\chi^{2}(10, \mathrm{~N}=302)=11.79, p=0.299$, and a robust $\mathrm{CFI}=0.999$, were found for this solution.

Since all models resulted in robust fit indices, the root mean square error of approximation with $90 \%$ confidence intervals, the goodness of fit, adjusted goodness of fit, the Akaike information criterion (AIC), and the consistent Akaike information criterion (CAIC) were examined and evaluated against published guidelines (Bentler 1990; Hu et al. 1992; Tabachnick \& Fidell 2007). For comparative purposes, indices for all three models are listed in Table 4. Robust goodness of fit was found for all three models; however, the consistent Akaike information criterion indicates that the one-factor solution, as was found initially in our EFA, might provide the best underlying structure of the TDI. Considering the principle of parsimony, and given the relatively high intercorrelation between both subscales, the one-factor model was found to be most appropriate.

\section{Internal Consistency}

Reliability of the TDI was assessed on the whole sample and on the two subsamples separately. Internal consistency proved to be excellent, with Cronbach's alpha $=0.89$ (total sample), 0.89 (calibration sample), and 0.90 (validation sample).

\section{Reproducibility}

Test-retest reliability was assessed by calculating an intraclass correlation coefficient between the test sample (first assessment $=\mathrm{T} 0, \mathrm{~N}=143$ ) and retest sample (second assessment $=\mathrm{T} 1$, mean time interval of $4 \mathrm{wks}, \mathrm{N}=143$ ), using a two-way random effects model. Since tinnitus-related disability was expected to be a fairly stable construct, especially over this short period of time, the intraclass correlation coefficient of total TDI scores $(r=0.76, p<0.001)$ points out good single measure of test-retest reliability.

\section{Construct Validity}

To investigate construct validity of the TDI associations between the TDI, tinnitus intensity, the SF36, and the TQ were investigated using a subset $(\mathrm{N}=385)$ of the total sample.

\section{Correlations}

Pearson correlation coefficients were calculated to test bivariate associations between all variables (see Table 5). As was expected, correlations between the TDI, tinnitus intensity, the SF36, and the TQ were moderate (ranging from 0.46 to $0.71)$ but statistically significant.

\section{Regression Analyses}

A stepwise hierarchical regression analysis was carried out to investigate which of the measures uniquely contributed to the variance in tinnitus disability, controlled for age, gender, and education. The first step in the analysis included the control variables age, gender, and education. This model yielded no significant $F$ value $\left(R^{2}=0.01, F=1.44, p=0.08\right)$. Tinnitus intensity and the SF36 were added in the steps 2 and 3 of the hierarchical regression (see Table 5) and significantly contributed to total explained variance of disability due to tinnitus $\left(R^{2}=0.24, F=29.73, p=0.00 ; R^{2}=0.34, F=39.6\right.$, $p=0.00)$. Last, the TQ was added. Results showed that tinnitus severity added significantly to the model with an extra 


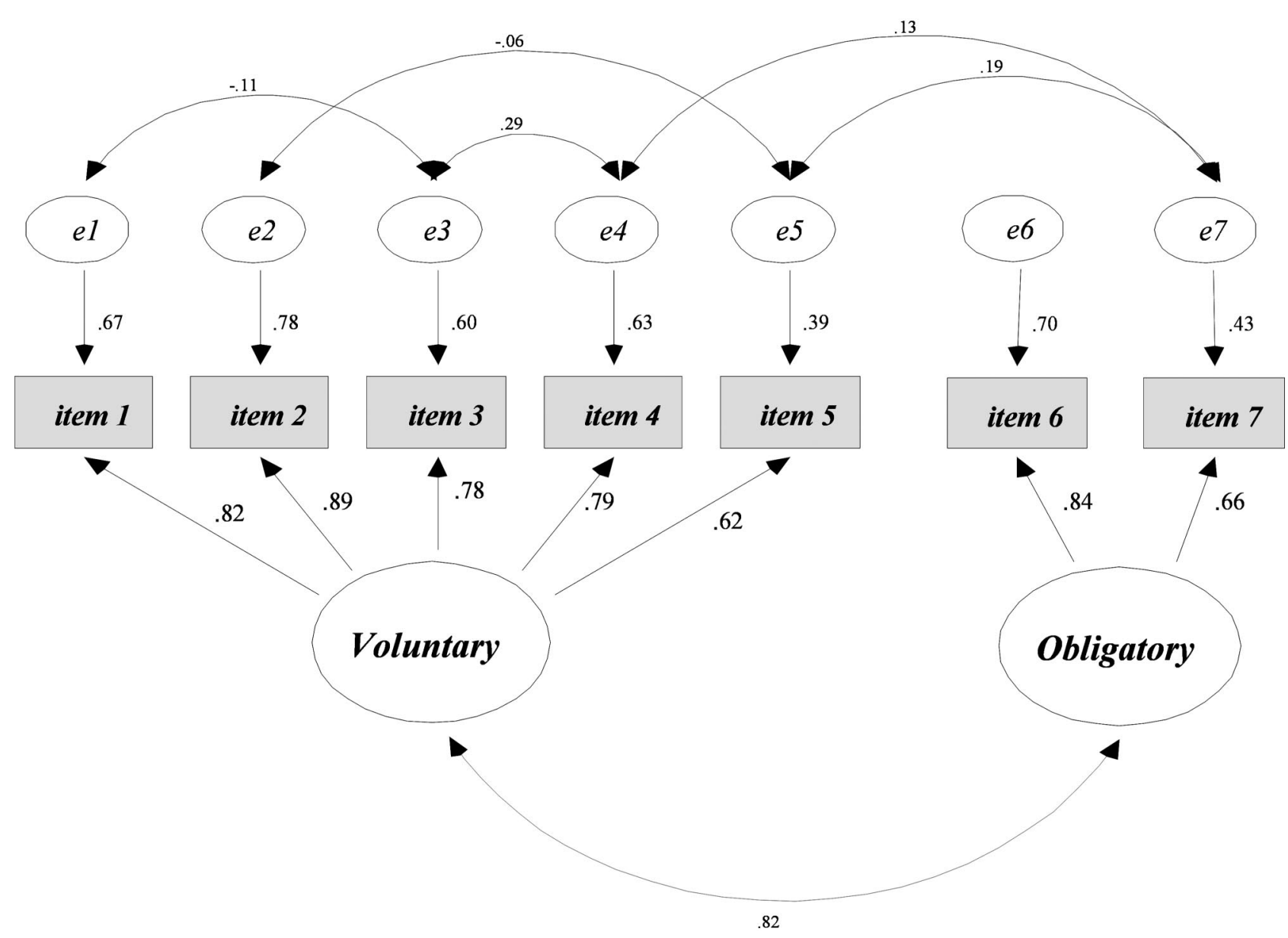

Fig. 3. Two-factor solution, modeled after the Pain Disability Index, with standardized estimates and added covariances.

$22 \%$ of explained variance $\left(R^{2}\right.$ change $\left.=0.22, p<0.001\right)$. In the final step, education reached significance (see Table 6) (total model: $R^{2}=0.56, F=81.3, p=0.00$ ). There was no problem of multicollinearity between the independent variables (VIF's $\leq 1.85)$.

\section{DISCUSSION}

Although several measures exist that can be used to quantify the impact of tinnitus complaints on patients' cognitive, emotional, physical, and even auditory functioning, currently there is no measure available that specifically focuses on functional disability, that is, the interference of tinnitus with performance on major daily life activities. In the present study, a slightly adapted version of the PDI resulting in the TDI was administered to a large sample of individuals suffering from tinnitus. A first psychometric examination of this novel measure was carried out, includ- ing factor structure analysis and the analysis of internal consistency, reproducability, and construct validity.

A principal component analysis on a random-split calibration sample generated a one-factor solution accounting for $60 \%$ of explained variance. Since the TDI is a brief inventory, this unitary solution was judged to be appropriate. This model was verified in a confirmatory factor analysis on the validation sample after three significant fit modifications were applied. Consistent with earlier findings from Tait et al. (1990) studying pain disability, as measured with the PDI, a second factor was forced using the calibration sample. The resulting two-factor solution was currently found to account for $>72 \%$ of total variance. It is interesting to note that these findings did not corroborate PDI findings entirely. Although two internally consistent factors were generated, the factor loadings revealed different loadings of items on the factors than expected. Confirmatory factor analysis resulted in a robust and parsimo-

TABLE 4. Fit indices of the one-factor and both two-factor solutions with confirmatory factor analysis

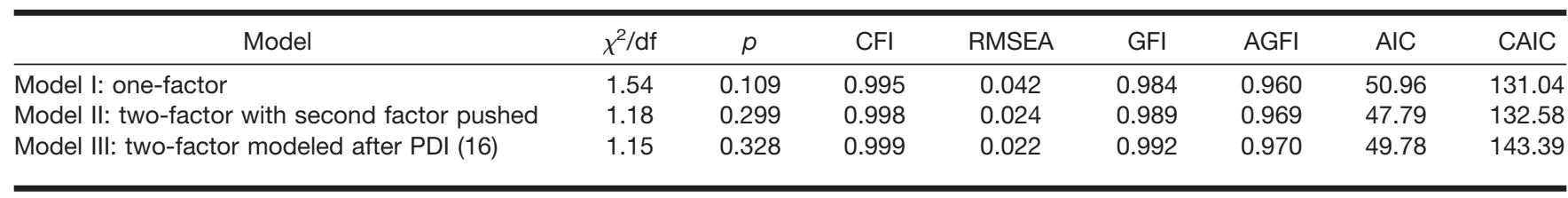


TABLE 5. Means, standard deviations, and Pearson correlation coefficients

\begin{tabular}{lcrcccc}
\hline & Mean & SD & TDI & Intensity & SF36 & TQ \\
\hline Intensity & 57.1 & 19.9 & $0.48^{*}$ & - & $0.29^{*}$ & $0.59^{*}$ \\
SF36 & 45 & 9.1 & $0.46^{*}$ & $0.29^{*}$ & - & $0.44^{*}$ \\
TQ & 45.6 & 18.8 & $0.71^{*}$ & $0.59^{*}$ & $0.44^{*}$ & - \\
Age & 53.5 & 11.2 & -0.07 & 0.04 & $-0.09 \dagger$ & 0.02 \\
Duration & 5.4 & 1.5 & 0.02 & $0.13 \dagger$ & -0.05 & 0.02 \\
Gender & - & - & -0.01 & 0.03 & -0.01 & -0.08 \\
Education & - & - & -0.08 & $-0.19 \dagger$ & $-0.13^{*}$ & $-0.25^{*}$ \\
& & & & & & \\
\hline
\end{tabular}

* Correlation is significant at the 0.01 level (two tailed).

+ Correlation is significant at the 0.05 level (two tailed).

nious two-factor solution for this model. In order to investigate the comparative fit of the two-factor solution proposed by Tait and others (Tait et al. 1990; Tait \& Chibnall 2005; Gauthier et al. 2008), this model was also investigated using confirmatory analysis. Again, fit indices revealed a robust and parsimonious model. However, reliability analysis showed that the one- and two-factor models currently investigated had internally consistent subscales ranging from good to excellent, whereas the obligatory subscale of the Tait model was not reliable.

Comparative fit indices showed that both two-factor models did not have a better fit over the one-factor solution found initially in our calibration sample. This led to the conclusion that the one-factor structure was most parsimonious and this unitary model was adopted. Corroborating these findings, the test-retest reliability of the TDI as a one-factor measure over a 4 -wk period proved to be satisfactory as well.

Robust evidence was found for construct validity of the TDI. Tinnitus-related disability was expected to be associated with tinnitus intensity, ratings of general health, and tinnitus severity. Pearson correlations among measures of tinnitus intensity, quality of life (SF36), and tinnitus distress (TQ) are relatively low, suggesting that disability as measured with the TDI is conceptually distinct from the other tinnitus-related constructs, and that it seems to measure a unique underlying construct. Tinnitus intensity, as measured with three different VAS, was found to be significantly associated with ratings of tinnitus disability. Furthermore, general health significantly contributed to the model above and beyond tinnitus intensity, suggesting that participants with poorer general health reported more interference of the tinnitus in daily life activities. Tinnitus severity or distress due to tinnitus, finally, was an additional predictor of tinnitus-related disability, again above and beyond tinnitus intensity, and general health. The relatively low $\beta$ values suggest that other factors are likely to influence tinnitus disability, of which perceived threat value and tinnitusrelated fear responses are good candidates. Indeed, the predictive value of these factors on disability have been well established in chronic pain research (Crombez et al. 1999; Vlaeyen \& Linton 2000; Leeuw et al. 2007; Gheldof et al. 2010; Jensen et al. 2010), and it would be interesting to investigate whether fear of tinnitus is as disabling as the tinnitus itself, or perhaps more so (Crombez et al. 1999).

There are some limitations worth mentioning concerning the current investigation. First, these results concern cross-sectional data, and causality cannot be inferred from regression analyses. Experimental manipulations of the suggested predictors are needed in future research to scrutinize the causal pathways that lead to tinnitus disability. Second, audiometrical measurements, such as level and lateralization of hearing loss, tinnitus pitch match frequency, and maskability, were not available and consequently were not taken into account in the present study. Future research investigating how audiometric data are associated with disability due to tinnitus in daily life is needed, since earlier reports suggest that audiological dysfunctions such as hearing loss and hyperacusis are associated with tinnitus impairment (Andersson 2003; Holgers et al. 2005). Third, a self-selection bias may have occurred because of the web-based administration of the questionnaires in this study. Although participants were given the opportunity to complete the battery off-line as a classical paper and pencil test as well, the majority of respondents completed the measures online. It could be argued that individuals without computer skills, or not in possession of a PC, occur mainly in the older population and might be underrepresented in the present study. However, the mean age of participants does not seem to imply overrepresentation of younger respondents in the present study. Fourth, it should be noted that most respondents completed the online version of the TDI, and therefore we can conclude that the psychometric qualities of the electronic version of the TDI have been currently established. The web-based nature of the present study is, on the other hand, in line with recent developments in research and the trend to offer online therapy and measurements (Andersson \& Kaldo 2004; Kaldo et al. 2008; Abbott et al. 2009). Fifth, it should be noted that the current investigation was carried out in a Dutch-speaking population. The validity of the TDI in other languages still has to be established. Last, correlations might be artificially increased because of shared method variance.

Results provide firm support that the TDI, as a unitary brief index, is reliable over time and is a valid measure for assessing

TABLE 6. Results of hierarchical regression analysis with tinnitus disability as dependent variable

\begin{tabular}{|c|c|c|c|c|c|c|c|c|c|c|c|c|}
\hline $\begin{array}{l}\text { Independent } \\
\text { variable }\end{array}$ & \multicolumn{3}{|c|}{ Step 1} & \multicolumn{3}{|c|}{ Step 2} & \multicolumn{3}{|c|}{ Step 3} & \multicolumn{3}{|c|}{ Step 4} \\
\hline Age & -0.06 & 0.24 & & -0.07 & 0.11 & & -0.02 & 0.58 & & -0.05 & 0.17 & \\
\hline Education & -0.10 & 0.07 & 0.01 & -0.01 & 0.91 & & 0.03 & 0.50 & & 0.11 & 0.03 & \\
\hline Tinnitus intensity & & & & 0.49 & 0.00 & $0.24^{\star}$ & 0.39 & 0.00 & & 0.08 & 0.08 & \\
\hline General health & & & & & & & 0.34 & 0.00 & $0.34^{*}$ & 0.17 & 0.00 & \\
\hline
\end{tabular}


tinnitus-related disability. When examining the two-factor structure, the findings are not entirely synchronous with those in chronic pain patients. Even though parallels between chronic pain and chronic tinnitus have been described, important differences may exist as well. In chronic pain patients, interference with voluntary and involuntary activities by pain might be different from the interference with these activities by tinnitus in tinnitus patients. This is possibly because physical movement is probably much more compromised in chronic pain as compared with tinnitus patients. Also, the behavioral responses to chronic pain and tinnitus are likely to be different. Future research should be aimed at investigating the nature of these behavioral responses in tinnitus patients and how they affect disability.

The TDI may constitute a valuable addition to the commendable tools already in use for several reasons. First, it is a brief and easily administered index. Second, it appears to capture a unique construct, namely tinnitus disability, or the experienced interference of the tinnitus with daily life activities, which is invaluable in the assessment and treatment of tinnitus patients. Third, medical insurance companies often address issues such as impact on daily living or impairment in daily life when investigating whether the treatment is covered for a particular patient or not, which is imperative for treatment options for clinicians. Fourth, the TDI is notable for the limited confounding content overlap with other constructs, such as psychological distress, audiological impairment, or general health (Nicholls et al. 1982). Therefore, the TDI might be particularly useful in comparative effectiveness studies of existing and novel tinnitus interventions, as well as in experimental research, aimed at disentangling the neurocognitive and behavioral mechanisms underlying tinnitus disability.

\title{
APPENDIX: TINNITUS DISABILITY INDEX
}

\begin{abstract}
The rating scales below are designed to measure the degree to which several aspects of your life are presently disrupted by the tinnitus. In other words, we would like to know how much the tinnitus is preventing you from doing what you normally do, or from doing it as well as you normally would. Respond to each category by indicating the overall impact of the tinnitus in your life, not just when the tinnitus is at its worst.

For each of the 7 categories of life activity listed, please circle the number on the scale which describes the level of disability you typically experience. A score of 0 means no disability at all, and a score of 10 signifies that all of the activities in which you would normally be involved have been totally disrupted or prevented by your tinnitus.
\end{abstract}

\section{Family/home responsibilities}

This category refers to activities related to the home or family. It includes chores or duties performed around the house (e.g. yard work) and errands or favours for other family members (e.g. driving the children to school).

\begin{tabular}{lrllllllllr}
0 & 1 & 2 & 3 & 4 & 5 & 6 & 7 & 8 & 9 & 10 \\
\hline $\begin{array}{l}\text { No } \\
\text { disability }\end{array}$ & & & & & & & & & $\begin{array}{r}\text { Total } \\
\text { disability }\end{array}$
\end{tabular}

2. Recreation

This category includes hobbies, sports, and other similar leisure time activities.

\begin{tabular}{llllllllllr}
0 & 1 & 2 & 3 & 4 & 5 & 6 & 7 & 8 & 9 & 10 \\
\hline $\begin{array}{l}\text { No } \\
\text { disability }\end{array}$ & & & & & & & & & $\begin{array}{r}\text { Total } \\
\text { disability }\end{array}$
\end{tabular}

3. Social activity

This category refers to activities which involve participation with friends and acquaintances other than family members. It includes parties, theatre, concerts, dining out, and other social functions.

\begin{tabular}{llllllllllr}
0 & 1 & 2 & 3 & 4 & 5 & 6 & 7 & 8 & 9 & 10 \\
\hline $\begin{array}{l}\text { No } \\
\text { disability }\end{array}$ & & & & & & & & & $\begin{array}{r}\text { Total } \\
\text { disability }\end{array}$
\end{tabular}

4. Occupation

This category refers to activities that are part of or directly related to one's job. This includes non-paying jobs as well, such as that of a housewife or a volunteer worker.

\begin{tabular}{llllllllllr}
0 & 1 & 2 & 3 & 4 & 5 & 6 & 7 & 8 & 9 & 10 \\
\hline $\begin{array}{l}\text { No } \\
\text { disability }\end{array}$ & & & & & & & & & $\begin{array}{r}\text { Total } \\
\text { disability }\end{array}$
\end{tabular}

5. Sexual behaviour

This category refers to the frequency and quality of one's sex life.

\begin{tabular}{lllllllllll}
0 & 1 & 2 & 3 & 4 & 5 & 6 & 7 & 8 & 9 & 10 \\
\hline $\begin{array}{l}\text { No } \\
\text { disability }\end{array}$ & & & & & & & & & & $\begin{array}{r}\text { Total } \\
\text { disability }\end{array}$
\end{tabular}

6. Self-care

This category includes activities which involve personal maintenance and independent daily living (e.g. taking a shower, driving, getting dressed, etc.).

\begin{tabular}{llllllllllr}
0 & 1 & 2 & 3 & 4 & 5 & 6 & 7 & 8 & 9 & 10 \\
\hline $\begin{array}{l}\text { No } \\
\text { disability }\end{array}$ & & & & & & & & & $\begin{array}{r}\text { Total } \\
\text { disability }\end{array}$
\end{tabular}

7. Life-support activity

This category refers to basic life-supporting behaviours such as eating, sleeping and breathing.

\begin{tabular}{lllllllllll}
0 & 1 & 2 & 3 & 4 & 5 & 6 & 7 & 8 & 9 & 10 \\
\hline $\begin{array}{l}\text { No } \\
\text { disability }\end{array}$ & & & & & & & & & $\begin{array}{r}\text { Total } \\
\text { disability }\end{array}$
\end{tabular}




\section{ACKNOWLEDGMENTS}

The authors thank the Dutch Association for hearing disorders (www. nvvs.nl) and the Dutch Tinnitus Platform (www.tinnitus.nl) for placing advertisements on their websites and providing online information about the study to all visitors. They also thank Rosanne Janssen for assisting with the online application "Emium" and the Maastricht University, Faculty of Psychology and Neuroscience, for enabling online registration for participants. The authors specially thank all participating tinnitus patients from across The Netherlands.

This work was supported by ZonMw, Grant number 945-07-715 (to R.F.F.C. and J.W.S.V.).

Address for correspondence: Rilana F. F. Cima, MSc, MTD, Department of Clinical Psychological Science, Mastricht University, 6200 MD Maastricht, The Netherlands. E-mail: r.cima@maastrichtuniversity.nl.

Received July 26, 2010; accepted December 28, 2010.

\section{REFERENCES}

Abbott, J. A., Kaldo, V., Klein, B., et al. (2009). A cluster randomised trial of an internet-based intervention program for tinnitus distress in an industrial setting. Cogn Behav Ther, 38, 162-173.

Andersson, G. (2003). Tinnitus loudness matchings in relation to annoyance and grading of severity. Auris Nasus Larynx, 30, 129-133.

Andersson, G., \& Kaldo, V. (2004). Internet-based cognitive behavioral therapy for tinnitus. J Clin Psychol, 60, 171-178.

Andersson, G., \& McKenna, L. (2006). The role of cognition in tinnitus. Acta Otolaryngol Suppl, 126, 39-43.

Arbuckle, J. L. (2006). AMOS 17.0 [software package]. Chicago, IL: SmallWaters.

Baguley, D. M., Humphriss, R. L., Hodgson, C. A. (2000). Convergent validity of the tinnitus handicap inventory and the tinnitus questionnaire. J Laryngol Otol, 114, 840-843.

Bentler, P. M. (1990). Comparative fit indexes in structural models. Psychol Bull, 107, 238-246.

Coles, R. R. A., Lutman, M. E., Axelsson, A., et al. (1991). Tinnitus Severity Gradings: Cross-sectional Studies. In J.-M. Aran \& R. Dauman (Eds.). Tinnitus '91: Proceedings of the Fourth International Tinnitus Seminar, Bordeaux, France, August 27-30 (pp. 453-455). Amsterdam/ New York: Kugler Publications.

Crombez, G., Vlaeyen, J. W., Heuts, P. H., et al. (1999). Pain-related fear is more disabling than pain itself: Evidence on the role of pain-related fear in chronic back pain disability. Pain, 80, 329-339.

El Refaie, A., Davis, A., Kayan, A., et al. (2004). A questionnaire study of the quality of life and quality of family life of individuals complaining of tinnitus pre- and post-attendance at a tinnitus clinic. Int J Audiol, 43, $410-416$.

Erlandsson, S. I., \& Hallberg, L. R. (2000). Prediction of quality of life in patients with tinnitus. Br J Audiol, 34, 11-20.

Folmer, R. L., Griest, S. E., Martin, W. H. (2001). Chronic tinnitus as phantom auditory pain. Otolaryngol Head Neck Surg, 124, 394-400.

Gauthier, N., Thibault, P., Adams, H., et al. (2008). Validation of a French-Canadian version of the Pain Disability Index. Pain Res Manag, 13, 327-333.

Gheldof, E. L., Crombez, G., Van den Bussche, E., et al. (2010). Pain-related fear predicts disability, but not pain severity: A Path analytic approach of the fear-avoidance model. Eur J Pain, 14, 870.e1870.e9.

Gronblad, M., Hupli, M., Wennerstrand, P., et al. (1993). Intercorrelation and test-retest reliability of the Pain Disability Index (PDI) and the Oswestry Disability Questionnaire (ODQ) and their correlation with pain intensity in low back pain patients. Clin J Pain, 9, 189-195.

Hallam, R. S., McKenna, L., Shurlock, L. (2004). Tinnitus impairs cognitive efficiency. Int J Audiol, 43, 218-226.

Hays, R. D., Sherbourne, C. D., Mazel, R. M. (1993). The RAND 36-Item Health Survey 1.0. Health Econ, 2, 217-227.

Heller, A. J. (2003). Classification and epidemiology of tinnitus. Otolaryngol Clin North Am, 369, 239-248.

Hiller, W., \& Goebel, G. (2006). Factors influencing tinnitus loudness and annoyance. Arch Otolaryngol Head Neck Surg, 132, 1323-1330.
Holgers, K. M., Zoger, S., Svedlund, K. (2005). Predictive factors for development of severe tinnitus suffering-further characterisation. Int $J$ Audiol, 44, 584-592.

Hu, L. T., Bentler, P. M., Kano, Y. (1992). Can test statistics in covariance structure analysis be trusted? Psychol Bull, 112, 351-362.

Janssen, R. (2008). Emium; Effect Monitoring via Internet Universiteit Maastricht. Version 1.3. Maastricht: Research Institute of Experimental Psychopathology, Maastricht University.

Jastreboff, P. J. (1990). Phantom auditory perception (tinnitus): Mechanisms of generation and perception. Neurosci Res, 8, 221-254.

Jastreboff, P. J., \& Hazell, J. W. (1993). A neurophysiological approach to tinnitus: Clinical implications. Br J Audiol, 27, 7-17.

Jastreboff, P. J., \& Hazell, J. W. P. (2004). Tinnitus Retraining Therapy: Implementing the Neurophysiological Model. Cambridge: Cambridge University Press.

Jensen, J. N., Karpatschof, B., Labriola, M., et al. (2010). Do fearavoidance beliefs play a role on the association between low back pain and sickness absence? A prospective cohort study among female health care workers. J Occup Environ Med, 52, 85-90.

Jerome, A., \& Gross, R. T. (1991). Pain disability index: Construct and discriminant validity. Arch Phys Med Rehabil, 72(11), 920-922.

Kaldo, V., Levin, S., Widarsson, J., et al. (2008). Internet versus group cognitive-behavioral treatment of distress associated with tinnitus: A randomized controlled trial. Behav Ther, 39, 348-359.

Kamalski, D. M., Hoekstra, C. E., van Zanten, B. G., et al. (2010). Measuring disease-specific health-related quality of life to evaluate treatment outcomes in tinnitus patients: A systematic review. Otolaryngol Head Neck Surg, 143, 181-185.

Kuk, F. K., Tyler, R. S., Russell, D., et al. (1990). The psychometric properties of a tinnitus handicap questionnaire. Ear Hear, 11, 434-445.

Leeuw, M., Goossens, M. E., Linton, S. J., et al. (2007). The fearavoidance model of musculoskeletal pain: Current state of scientific evidence. J Behav Med, 30, 77-94.

Martinez Devesa, P., Waddell, A., Perera, R., et al. (2007). Cognitive behavioural therapy for tinnitus. Cochrane Database Syst Rev, CD005233.

McCombe, A., Baguley, D., Coles, R., et al. (2001). Guidelines for the grading of tinnitus severity: The results of a working group commissioned by the British Association of Otolaryngologists, Head and Neck Surgeons, 1999. Clin Otolaryngol Allied Sci, 26(5), 388-393.

Meikle, M. B., Griest, S. E., Stewart, B. J., et al. (1995). Measuring the negative impact of tinnitus: A brief severity index. Abstr Assoc Res Otolaryngol, 167.

Meikle, M. B., Stewart, B. J., Griest, S. E., et al. (2007). Assessment of tinnitus: Measurement of treatment outcomes. Prog Brain Res, 166, 511-521.

Mosges, R., Koberlein, J., Erdtracht, B., et al; RHEO-ISHL Study Group. (2008). Quality of life in patients with idiopathic sudden hearing loss: Comparison of different therapies using the Medical Outcome Short Form (36) Health Survey questionnaire. Otol Neurotol, 29, 769-775.

Newman, C. W., Jacobson, G. P., Spitzer, J. B. (1996). Development of the Tinnitus Handicap Inventory. Arch Otolaryngol Head Neck Surg, 122, 143-148.

Nicholls, J. G., Licht, B. G., Pearl, R. A. (1982). Some dangers of using personality questionnaires to study personality. Psychol Bull, 92, 572580 .

Noble, W., \& Tyler, R. (2007). Physiology and phenomenology of tinnitus: Implications for treatment. Int $J$ Audiol, 46, 569-574.

Pollard, C. A. (1984). Preliminary validity study of the pain disability index. Percept Mot Skills, 59, 974.

Reitsma, B., \& Meijler, W. J. (1997). Pain and patienthood. Clin J Pain, $13,9-21$.

SPSS. (2009). SPSS 15.0 [software package]. Chicago, IL: IBM.

Stevens, C., Walker, G., Boyer, M., et al. (2007). Severe tinnitus and its effect on selective and divided attention. Int J Audiol, 46, 208-216.

Tabachnick, B. G., \& Fidell, L. S. (2007). Using Multivariate Statistics (5 ed.). Boston, MA: Allyn and Bacon.

Tait, R. C., \& Chibnall, J. T. (2005). Factor structure of the pain disability index in workers compensation claimants with low back injuries. Arch Phys Med Rehabil, 86, 1141-1146.

Tait, R. C., Chibnall, J. T., Krause, S. (1990). The Pain Disability Index: Psychometric properties. Pain, 40, 171-182. 
Tonndorf, J. (1987). The analogy between tinnitus and pain: A suggestion for a physiological basis of chronic tinnitus. Hear Res, 28, 271-275.

Tyler, R. S., Aran, J.-M., Dauman, R. (1992). Recent advances in tinnitus. Am J Audiol, 1, 36-44.

Vlaeyen, J. W., \& Linton, S. J. (2000). Fear-avoidance and its consequences in chronic musculoskeletal pain: A state of the art. Pain, 85, 317-332.

Ware, J. E., Jr., Kosinski, M., Gandek, B., et al. (1998). The factor structure of the SF-36 Health Survey in 10 countries: Results from the IQOLA
Project. International Quality of Life Assessment. J Clin Epidemiol, 51, $1159-1165$.

Wilson, P. H., Henry, J., Bowen, M., et al. (1991). Tinnitus reaction questionnaire: Psychometric properties of a measure of distress associated with tinnitus. J Speech Hear Res, 34, 197-201.

Zachriat, C., \& Kroner-Herwig, B. (2004). Treating chronic tinnitus: Comparison of cognitive-behavioural and habituation-based treatments. Cogn Behav Ther, 33, 187-198.

\section{Erratum}

Identifying Cochlear Implant Channels with Poor Electrode-Neuron Interface: Partial Tripolar, Single-Channel Thresholds and Psychophysical Tuning Curves: Erratum

In the article that appeared on page 247 of the April 2010 issue of Ear and Hearing, it was reported that all subjects were implanted with the HiFocus $1 \mathrm{~J}$ electrode array with a center-to-center electrode distance of $1.1 \mathrm{~mm}$. However, three of the original subjects had actually been implanted with the Helix array with electrode spacing of 0.85 mm (Helix array: S22, S23, and S24), leading to erroneous calculations of the psychophysical tuning curve slopes and widths (expressed in $\mathrm{dB} / \mathrm{mm}$ and $\mathrm{mm}$, respectively). The slope and width values for these subjects, and all related statistics, have been subsequently recalculated using the correct electrode spacing. The new calculations do not change the results or overall conclusions of the article; therefore, updated figures will not be reprinted. For reference, the following table lists the corrected statistics, sorted by figure.

The authors sincerely regret the error.

The affected figures are:

Figure 6 (p. 254). Summary of PTC slope calculations.

Figure 7 (p. 255). Summary of PTC width and depth calculations.

Figure 10 (p. 256). Summary of lower probe level PTC slopes, widths and depths calculations.

\begin{tabular}{|c|c|c|c|c|}
\hline & Published & Corrected & Published & Corrected \\
\hline FIGURE 6 & \multicolumn{2}{|c|}{ Apical Side } & \multicolumn{2}{|c|}{ Basal Side } \\
\hline Monopolar $\sigma=0$ & $r=-0.660^{\star}$ & $r=-0.786^{*}$ & $r=-0.220$ & $r=-0.321$ \\
\hline (Spearman rank correlation) & $p=0.013$ & $p=0.001$ & $p=0.500$ & $p=0.365$ \\
\hline Tripolar $\sigma \geq 0.55$ & $r=-0.775^{\star}$ & $r=-0.791^{*}$ & $r=-0.469$ & $r=-0.697^{*}$ \\
\hline (Spearman rank correlation) & $p=0.002$ & $p=0.001$ & $p=0.124$ & $p=0.025$ \\
\hline MP slope $x$ pTP slope & $z=-2.062$ & $z=-2.062$ & $z=-1.726$ & $z=-1.070$ \\
\hline (Wilcoxon Signed Rank) & $\mathrm{p}=0.039$ & $\mathrm{p}=0.039$ & $\mathrm{p}=0.084$ & $\mathrm{p}=0.285$ \\
\hline \multicolumn{5}{|l|}{ FIGURE 7} \\
\hline Monopolar $\sigma=0$ & $r=0.470$ & $r=0.270$ & & \\
\hline (Spearman rank correlation) & $p=0.105$ & $p=0.013$ & & \\
\hline Tripolar $\sigma \geq 0.55$ & $r=0.476$ & $r=0.247$ & & \\
\hline (Spearman rank correlation) & $p=0.100$ & $p=0.415$ & & \\
\hline MP width $x$ pTP width & $z=-2.830$ & $z=-2.830$ & & \\
\hline (Wilcoxon Signed Rank) & $\mathrm{p}=0.005$ & $\mathrm{p}=0.005$ & & \\
\hline FIGURE 10 & \multicolumn{2}{|c|}{ Apical Side } & \multicolumn{2}{|c|}{ Basal Side } \\
\hline Monopolar $\sigma=0$ (probe at $+1.5 \mathrm{~dB}$ ) & $r=-0.857^{*}$ & $r=-0.762^{*}$ & $r=-0.714$ & $r=-0.643$ \\
\hline (Spearman rank correlation) & $p=0.007$ & $p=0.028$ & $p=0.071$ & $p=0.119$ \\
\hline \multicolumn{5}{|c|}{ PTC width } \\
\hline Monopolar $\sigma=0$ (probe at $+1.5 \mathrm{~dB}$ ) & 0.643 & $r=-0.738^{*}$ & & \\
\hline (Spearman rank correlation) & 0.086 & $p=0.037$ & & \\
\hline
\end{tabular}

\section{Reference:}

Bierer, J. A., \& Faulkner, K. F. (2010). Identifying cochlear implant channels with poor electrode-neuron interface: Partial tripolar, single-channel thresholds and psychophysical tuning curves. Ear Hear 31, 247-258. 